\title{
Zooplankton spine induces aversion in small fish predators
}

\author{
D. Rae Barnhisel* \\ Department of Biology, and the University of Michigan Biological Station, University of Michigan, Ann Arbor, MI 48109, USA
}

Received March 25, 1991 / Accepted in revised form June 24, 1991

Summary. The spined cladoceran Bythotrephes cederstroemi is protected from small fish predators due to the difficulty small fish have in ingesting the spine. Juvenile yellow perch (Perca flavescens) $50-60 \mathrm{~mm}$ in length were offered Bythotrephes with alternative prey available in two experiments. First, perch were observed as they gained experience with Bythotrephes and developed aversion to the zooplankter. Perch initially attacked and captured Bythotrephes. However, they struggled to ingest the spined zooplankter, rejected and recaptured it many times, and finally ceased to attack it. Second, perch were offered Bythotrephes with varying portions of the spine removed to clarify the spine's role in inducing such behaviors. Perch showed greater preference to attack nospine and half-spine Bythotrephes, and were less likely to reject and more likely to ingest Bythotrephes with the spine removed. For small or young fish that forage on zooplankton in lakes where Bythotrephes is present, aversion is an efficient response to the conspicuous but unpalatable spined cladoceran. However, aversion allows Bythotrephes, also a predator on zooplankton, to more effectively compete with young fish without an increase in predation risk.

Key words: Predator defense - Bythotrephes cederstroemi - Cladoceran - Yellow perch - Behavior

Spines are useful structural defenses against predators in both terrestrial and aquatic systems, as a permanent feature to harm a potential predator (Edmunds 1974), or induced by the presence of a predator to frustrate ingestion (Havel 1987). The mechanisms by which spines act include decreasing the accessibility of the prey item, increasing predator handling time, and/or increasing the

\footnotetext{
* Present address and address for offprint requests: Department of Biological Sciences, and Lake Superior Ecosystem Research Center, Michigan Technological University, Houghton, MI 49931, USA
}

probability that the prey will escape or be rejected, or the predator will be injured (Hoogland et al. 1957; Jacobs 1965; Gilbert 1966; Reist 1980; Havel and Dodson 1984; Harvell 1984; Young 1986; Forbes 1989; Morgan 1989; Barnhisel 1991). However, such post-contact mechanisms consume time and energy, and risk injury or death to both predator and prey. The likelihood that spines function in a more efficient pre-contact form of defense such as aversion to alert the predator of a timeconsuming food item, and reduce handling of the prey, is rarely explored.

Aversion to a prey item is a behavioral mechanism seen only in predators capable of learning. Classic examples involve food containing a chemical stimulus that induces nausea, vomiting, or intense pain. These include rat aversion to poison (Garcia et al. 1974), bird aversion to monarch butterflies that have fed on plants containing poison (Brower et al. 1967), frog aversion to stinging bumblebees (Brower and Brower 1962), octopus aversion to hermit crabs with sea anemones on their shell (Ross 1971), and fish aversion to brightly-colored water mites (Kerfoot 1982). In these cases, the predator learns aversion relatively quickly and usually requires only one or two exposures before it recognizes the food item and avoids it. While it certainly appears adaptive that animals learn to respond a priori to foods containing poisons or causing intense pain, aversion requires that the animal associate some characteristic of the prey item with feeding discomfort in order that it recognize and avoid similar prey in the future. The cue can be visual, auditory or olfactory, and may be mimicked according to Batesian or Müllerian theories (Fisher 1958). How quickly the animal learns aversion probably varies with the mechanism of the stimulus (nausea as opposed to localized pain) and its degree of negativity (intense pain to mild discomfort). However, the final response is active avoidance, escape, or inhibition from approaching a particular object (Lorenz 1981).

The spined cladoceran Bythotrephes cederstroemi is a common food item for adult fish in Eurasia and the 
North American Great Lakes, but it is not easily ingested by fish $<100 \mathrm{~mm}$. Bythotrephes has a fixed rigid spine 3-4 times its $2 \mathrm{~mm}$ body length (Fig. 1) that makes its ingestion by small fish difficult, increasing predator handling time eight-fold (Barnhisel 1991). As predator size decreases, fish manipulate the zooplankter for longer periods of time, and are often unlikely to ultimately ingest it (Barnhisel 1991).

To explore the spine's function in both post-contact and pre-contact defense, I document the response of juvenile yellow perch to Bythotrephes in two experiments. Naive perch are introduced to Bythotrephes with alternative prey to determine if fish develop aversion to the large invertebrate. Second, experienced perch are offered Bythotrephes with varying portions of the spine removed to determine how their response varies with changes in Bythotrephes' spine length.

\section{Methods}

Juvenile yellow perch (Perca flavescens) approximately 50-60 mm in standard length were seined from a private pond not containing Bythotrephes. The pond had been stocked previously with perch larvae hatched from eggs taken from Lake Huron (USA, Canada). Perch were transported to the University of Michigan Biological Station and maintained on artificial trout chow for two weeks prior to the first experiment and between experiments. For both experiments, perch were isolated in oxygenated aquaria lit from above by fluorescent bulbs. Light levels ranged from $16-21 \mu$ Einsteins $\mathrm{m}^{-2}$ $\mathrm{s}^{-1}$ among aquaria but remained constant for each aquarium. Water temperature averaged $21^{\circ} \mathrm{C}\left( \pm 2^{\circ} \mathrm{C}\right)$. Bythotrephes cederstroemi were collected from Grand Traverse Bay, Lake Michigan (USA) as needed from July to August 1989 , and maintained at $5^{\circ} \mathrm{C}$. Alternative prey consisted of Daphnia pulicaria approximately $2 \mathrm{~mm}$ in size, and diaptomid copepods approximately $1 \mathrm{~mm}$ in size, collected from Lancaster Lake and Douglas Lake, respectively, Cheboygan County, MI. Both are common food items for young perch (Mills and Forney 1981, Furnass 1979).

All prey items offered to perch were added simultaneously from the top of the aquarium. I visually observed all fish behavior, aided by a video camera with a running clock display and audio input that recorded the feeding trial and my observations. Data collected were the number and identity of prey items handled by fish, and the time, duration, and manner each prey item was handled.

\section{Feeding trials with alternative prey}

An important component of documenting aversion is to observe the predator's reaction to a food item over time. In the first experiment, 14 naive perch were introduced to Bythotrephes in the presence of alternative prey in eight feeding trials over a two-day period. Fish were isolated in aquaria screened on three sides and containing 61 of water, and tested over a three-week period with 4-8 fish tested at a time. Perch ranged in standard length from 49 to $59 \mathrm{~mm}$ (mean $=56 \pm 0.8 \mathrm{~mm}$ ). Prior to the experiment, fish were acclimated to their aquaria for 24-36 hours without food. For the first two days of the experiment, each fish was offered a prey mixture of 25 Daphnia and 25 copepods 3 times a day. Adult Bythotrephes (Fig. 1) were added to this prey mixture on the 3 rd and 4 th day for 4 times a day. On the 3rd day, 5 Bythotrephes were added; on the 4th day, 10 were added. On the 5 th day, fish were fed the initial prey mixture with no Bythotrephes added for 4 times a day. I observed fish feeding on prey items for not more than 5 min during a trial and waited a minimum of 15 min before initiating another trial on the same fish.

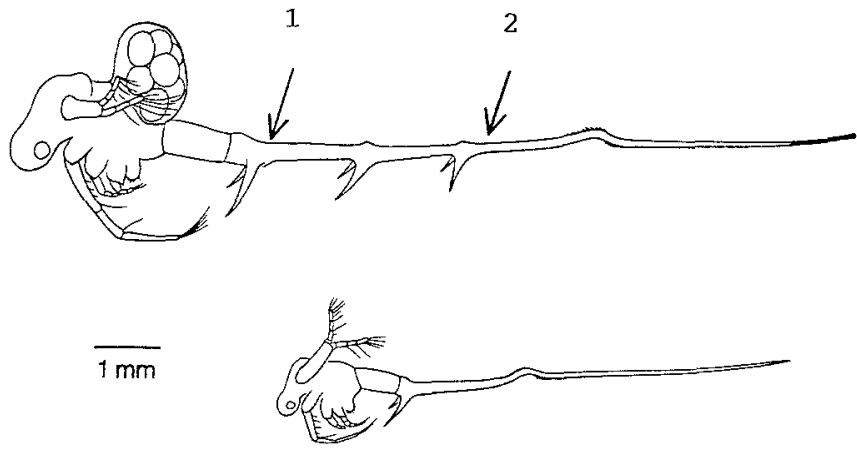

Fig. 1. Adult and juvenile Bythotrephes cederstroemi (From Evans 1988). Adult individuals approximately $1 \mathrm{~cm}$ in total length with three pairs of lateral barbs on the spine and juveniles approximately $6 \mathrm{~mm}$ in length with one pair of lateral barbs were used in the experiments. Arrows indicate points of excision for (1) no-spine and (2) half-spine animals used in the binary choice experiment

Table 1. Paired prey choices offered to juvenile yellow perch in the order indicated. Each perch was offered a pair of prey at least 5 times. Bythotrephes cederstroemi as a prey choice varied from adult individuals, with some having certain portions of the spine removed, to juvenile individuals. Daphnia pulicaria were approximately $2 \mathrm{~mm}$ in length and similar to those offered to perch in the first experiment. The number of fish (n) that responded to the Bythotrephes offered and included in that presentation's analysis are indicated

\begin{tabular}{llc}
\hline Paired Prey & & Fish (n) \\
\hline Bythotrephes-no spine & Daphnia & 17 \\
Bythotrephes-half spine & Daphnia & 17 \\
Bythotrephes-full spine & Daphnia & 14 \\
Bythotrephes-juvenile & Daphnia & 8 \\
Bythotrephes-no spine & Bythotrephes-full spine & 14 \\
\hline
\end{tabular}

\section{Multiple paired presentations}

I conducted a second experiment to explore how changes in Bythotrephes' spine length affects fish response and prey preference. After feeding trials with alternative prey had been completed, the perch were measured, returned to a central holding tank, and fed artificial fish food. Not less than 5 days later, perch were isolated and acclimated in individual aquaria.

In a single feeding period with multiple presentations (Table 1), I offered fish Daphnia pulicaria paired with a Bythotrephes with either the spine removed (no-spine), half the spine removed (halfspine), or none of the spine removed (full-spine). In addition, I offered perch Daphnia paired with juvenile Bythotrephes, and fullspine Bythotrephes paired with no-spine Bythotrephes. All fish were presented with a particular pair of items at least five times. Because all perch had previously experienced Bythotrephes, and most had shown aversion to it, the order in which I presented the paired prey items was crucial. Table 1 lists the order the paired prey were offered. Bythotrephes in the no-spine condition was presented first with Daphnia to initiate interest, followed by half-spine and fullspine individuals paired with Daphnia. Juvenile Bythotrephes have shorter and less rigid spines and so were offered to perch with Daphnia to determine the degree of their vulnerability to predators experienced with adult Bythotrephes.

All paired prey items were added simultaneously from the top of each aquarium to ensure that fish encountered prey items equally. I considered the first prey to be attacked and captured during a paired presentation to be the preferred prey item. This is based on the assumption that both prey items had an equal chance of being 
attacked and captured after encounter given that a fish predator was not foraging selectively. Fish that did not attack one of the prey items offered during a paired presentation were excluded from that presentation's analysis. Fish that would not attack no-spine Bythotrephes were excluded from the experiment.

A total of 20 fish, 4 fish tested at a time, were acclimated for the experiment. Perch ranged in standard length from 48 to $62 \mathrm{~mm}$ $($ mean $=55 \pm 1.1 \mathrm{~mm})$. Fig. 1 shows the relative size of adult and juvenile Bythotrephes offered. Also shown are points of excision to render a Bythotrephes in (1) the no-spine condition and (2) the half-spine condition. Full-spine condition involves no excision. Cutting the spine causes an initial loss of hemolymph but does not kill the animal or immediately alter its swimming movements (Barnhisel 1991).

\section{Results}

\section{Feeding trials}

On average, perch fed a mixture of daphnids and copepods during the first two days consumed primarily Daphnia (Barnhisel 1990). When Bythotrephes was added to the prey mixture, average perch consumption of Daphnia decreased and remained low until the 5th day when Bythotrephes was removed. Copepod consumption remained consistently low throughout the experiment (Barnhisel 1990).

Perch response to Bythotrephes changed dramatically over time. Fig. 2 illustrates the behavioral pathways perch followed while foraging on Bythotrephes. Given search of a prey item and encounter with Bythotrephes, fish either attacked and captured Bythotrephes, or avoided it and resumed searching. Given attack and capture, fish either ingested Bythotrephes or rejected it. Given rejection, fish either recaptured Bythotrephes or avoided it and resumed searching. To analyze behavior, I calculated the probability that a foraging behavior occurred given that the preceding behavior occurred (Holling 1966). Behavioral probabilities were calculated for each fish during a feeding trial and then averaged over all fish. Mean probabilities \pm SE are plotted over time in Fig. 3. Before probabilities were averaged over all fish, I used individual fish probabilities for each feeding trial to calculate the Spearman rank correlation coefficient, $r_{s}$,

Fig. 3A-D. Behavioral probabilities for perch preying on Bythotrephes in feeding trials with alternative prey. Values are the mean probabilities $\pm \mathrm{SE}$ averaged over all fish; $n=14$ fish unless otherwise indicated. Note that $\mathrm{n}$ decreases as fish cease to attack Bythotrephes. Spearman's coefficient of rank correlation, $r_{s}$, is given for each behavioral probability. (A) Probability of attack and capture of Bythotrephes given encounter decreased over time $\left(r_{s}=-0.566\right.$; $P<0.001)$. Density of Bythotrephes is assumed to be the number encountered. (B) Probability that Bythotrephes was rejected at least once given capture increased over time $\left(r_{s}=0.564 ; P<0.001\right)$. (C) Probability of recapture of Bythotrephes given a rejection decreased over time $\left(\mathrm{r}_{\mathrm{s}}=-0.398 ; P=0.002\right)$. (D) Probability of ultimate ingestion of Bythotrephes given initial capture decreased over time $\left(\mathrm{r}_{\mathrm{s}}=-0.523 ; P<0.001\right)$. Note that probabilities $\mathrm{B}$ and D will not sum to one because Bythotrephes can be rejected multiple times before being ultimately rejected or ingested. The probability of ultimate rejection is 1 - ultimate ingestion

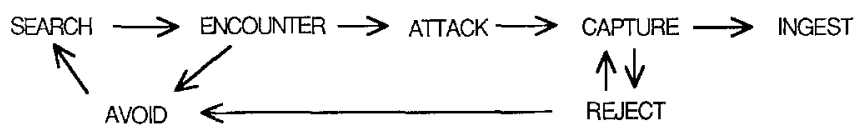

Fig. 2. Behavioral pathways for juvenile fish preying on Bythotrephes. Note that fish always capture a Bythotrephes they attack
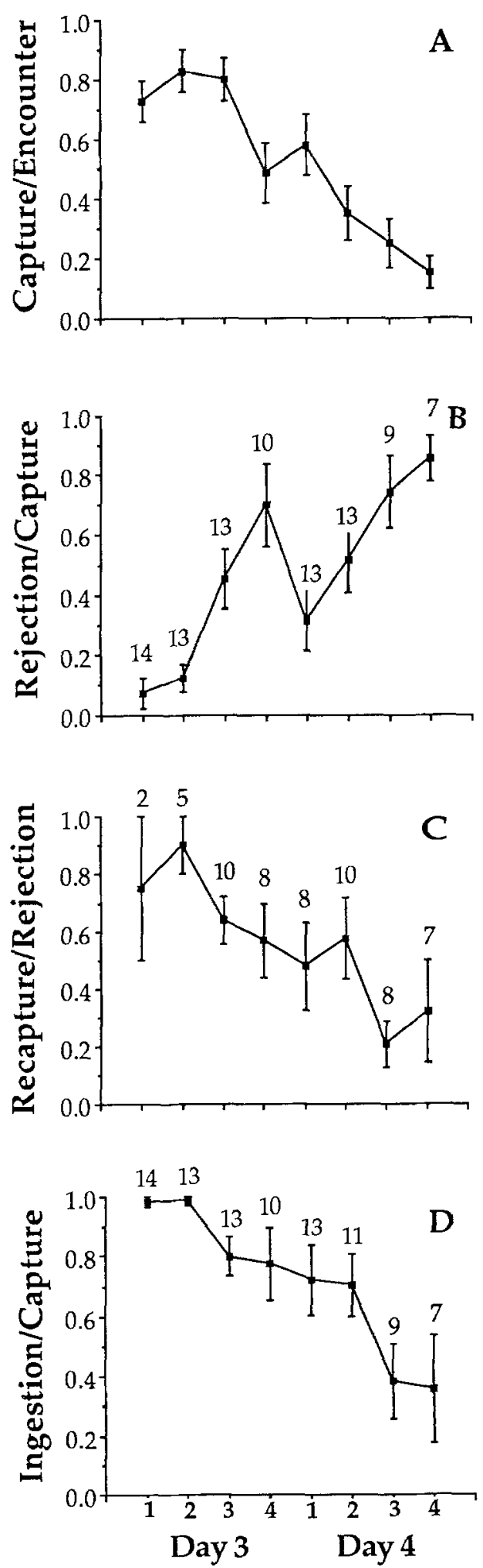
(Sokal and Rohlf 1981) to determine whether behavioral probabilities changed significantly over time. $\mathrm{P}$ and $\mathrm{r}_{\mathrm{s}}$ values are given in Fig. 3.

The probability that perch engaged in a particular behavior changed significantly over time. Naive fish responded to Bythotrephes immediately when it was introduced into their aquarium and were highly likely to capture and ingest Bythotrephes upon encounter (Fig. 3A, 3D). However, all perch had difficulty ingesting Bythotrephes, flared their operculi and buccal cavities, and often shook their heads and convulsed their bodies. These are typical responses seen in salmonids, coregonids and alewives under $100 \mathrm{~mm}$ feeding on Bythotrephes (reviewed in Barnhisel 1991) and similar to responses described by Hoogland et al. (1957) for perch feeding on spined sticklebacks. Capture and ingestion probabilities declined as fish rejected Bythotrephes at least once (Fig. 3B). Initially, perch repeatedly rejected and captured the same animal many times. One perch spent 14 seconds rejecting and recapturing a single Bythotrephes 5 times before it ultimately rejected it. The Bythotrephes was still alive. The rate of rejection at least once started out low on Day 4 when Bythotrephes density doubled (Fig. 3B) indicating a renewed interest to ingest the zooplankter due to either its increase in density or fish forgetting the previous day's encounter. However, the rejection rate again rose with each trial and with experience. Multiple rejections occurred more when recapture rates were high (Fig. 3C). With time perch were less likely to recapture a Bythotrephes they rejected, and an experienced perch would often reject a Bythotrephes immediately upon capture and make no attempt to ingest it. By the end of the experiment, ingestion rates had declined (Fig. 3D). Average Bythotrephes consumption declined from 4 to 2 individuals/trial when 5 Bythotrephes were offered and from 5 to 1 when 10 were offered. In addition, seven perch did not attack and capture Bythotrephes during the last two trials it was offered. Thus, $50 \%$ of the perch were averse to Bythotrephes by the end of the experiment.

\section{Paired presentations}

Of the 20 fish acclimated for the second experiment, all fish attacked and captured Daphnia. However, three fish refused to attack no-spine Bythotrephes, and so were excluded from all analyses. The remaining 17 fish attacked all prey items that were presented until full-spine Bythotrephes was offered. Only 14 of 17 fish attacked a full-spine Bythotrephes, eight of 17 fish attacked juvenile Bythotrephes, and 14 of 17 fish attacked a no-spine or full-spine Bythotrephes (Table 1).

To analyze perch choice of prey, I calculated for each fish the probability that it attacked one prey item first over another during a paired presentation. Then for each paired presentation, I calculated the mean probability $\pm \mathrm{SE}$ averaged over all fish and compared it to 0.5 , the probability one would expect if fish were foraging non-selectively and making choices randomly. Fig. 4. illustrates the average probabilities (mean $\pm \mathrm{SE}$;

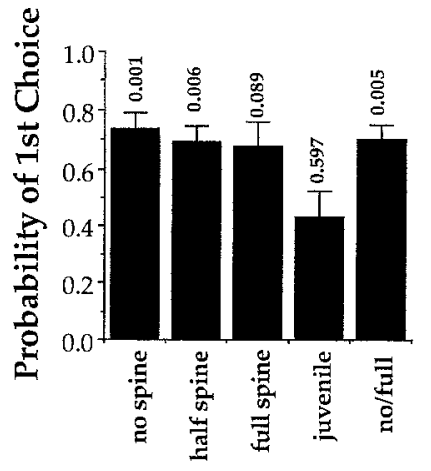

Fig. 4. Probability of Bythotrephes attacked first during the paired presentations. First four columns represent Bythotrephes (no-spine, half-spine, full-spine, or juvenile) attacked first over Daphnia; the fifth column shows no-spine Bythotrephes attacked first over a full-spine Bythotrephes. Column values are mean probabilities $\pm \mathrm{SE}$ averaged over all fish (n given in Table 1). Fish number (n) decreases as fish ceased to attack Bythotrephes. Means were compared to 0.5; $P$ values are given above each column
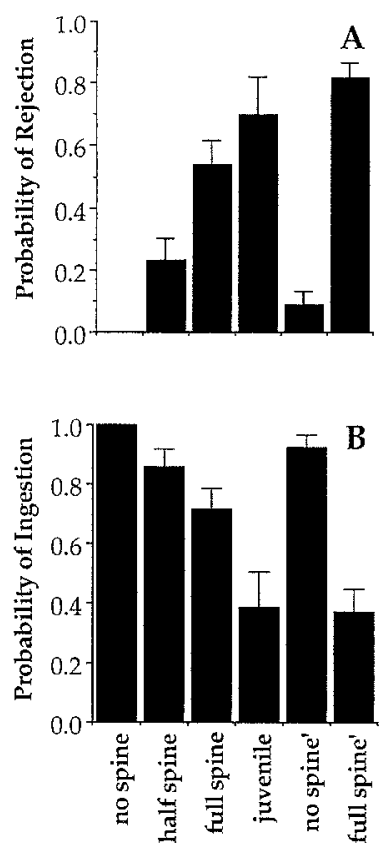

Fig. 5A, B. Probability of (A) rejection at least once and (B) ultimate ingestion given capture of Bythotrephes by perch in the second experiment. Values are mean probabilities $\pm \mathrm{SE}$ averaged for all fish (n given in Table 1). Here, rejection at least once indicates that the prey presented handling difficulty. Ultimate rejection is the inverse of ultimate ingestion. No-spine' and full-spine' are results from the fifth paired presentation

$\mathrm{n}=$ number of fish as in Table 1) that a fish attacked a Bythotrephes first over another prey item during each paired presentation. $P$ values were obtained by comparing the arcsine transformed average probabilities to the arcsine transformed 0.5 using Student's t-test (Sokal and Rohlf 1981). Perch significantly attacked a no-spine and half-spine Bythotrephes first over Daphnia, but did not attack a juvenile or full-spine Bythotrephes first over Daphnia. In the final paired presentation perch signifi- 
cantly attacked a no-spine Bythotrephes first over a fullspine form.

To determine whether the choices perch made during the second experiment were related to the handling and ingestion difficulty of the spine, I calculated the behavioral probabilities of rejection and ingestion given that a perch attacked a Bythotrephes in the no-spine, half-spine, full-spine, or juvenile condition. For each fish during a paired presentation, I calculated the probability that it rejected a Bythotrephes at least once and whether Bytho trephes was ultimately ingested, and averaged these over all fish (Fig. 5). To test for a significant relationship between spine length and probabilities of rejection and ingestion, I conducted two one-way analyses of variance using individual fish arcsine transformed probabilities of rejection and ingestion based on at least 5 presentations. The treatments were no-spine, half-spine and full-spine Bythotrephes of the first three presentations since these presentations differed only in spine length and were all paired with Daphnia. With increasing spine length left intact, the probability of rejecting a Bythotrephes significantly increased $(\mathrm{F}=24.36 ; \mathrm{df}=2 ; \mathrm{SS}=5.330$; $P<0.001$ ), and the probability of ingesting a Bythotrephes significantly decreased $(\mathrm{F}=8.87 ; \quad \mathrm{df}=2$; $\mathrm{SS}=1.921 ; P=0.001)$.

\section{Discussion}

Results from the multiple paired presentations clearly demonstrate what a preferred prey item Bythotrephes would be if not for its spine. Perch preferred to attack a no-spine Bythotrephes first over Daphnia and the fullspine Bythotrephes. Perch preference to attack a halfspine Bythotrephes first over Daphnia is also significantly higher than one would expect if choices were made randomly. However, perch had just finished feeding on nospine Bythotrephes and so may have been more inclined to attack the half-spine form. One must consider the results of one paired presentation to be intimately linked to the preceding presentation. A very different result would be expected if the fish had been divided into groups and each group was fed only one paired presentation.

Perch showed no preference for attacking a full-spine or juvenile Bythotrephes first over Daphnia indicating that their inclination to attack Bythotrephes was declining as more of the spine was left intact. In addition, fewer fish were willing to attack a Bythotrephes. Only 14 fish attacked a full-spine Bythotrephes, indicating that three fish had developed aversion to Bythotrephes while foraging on the half-spine form. Although all 17 fish were offered juvenile Bythotrephes paired with Daphnia, only eight fish attacked a juvenile Bythotrephes. Because juveniles are smaller and more transparent than adults, they may appear less conspicuous to fish. Alternatively, nine fish may have developed aversion to Bythotrephes from prior foraging on full-spine individuals. Regardless, juveniles do not appear to be more vulnerable to fish with their shorter, less rigid tail spines if fish have had previous experience with the adult forms.
Although perch hunger levels most probably decreased as the experiment progressed, satiation cannot explain the decreased interest in feeding. All 17 fish foraged on no-spine Bythotrephes presented in the fifth binary choice, although only 14 foraged on full-spine individuals. Results from the fifth choice indicate that fish significantly preferred to attack no-spine individuals and were able to distinguish them from full-spine Bythotrephes. It is unclear from the experiment, however, whether perch distinguished between no-spine and fullspine Bythotrephes on the basis of differences in behavior or differences in spine length. Regardless, perch consistent attack on no-spine Bythotrephes first over full-spine individuals indicates that the spine does indeed influence perch foraging decisions.

Different encounter rates of prey based on size, motion and transparency surely influenced perch foraging decisions during the experiment. Although a no-spine Bythotrephes and a Daphnia are approximately the same size, some difference in conspicuousness directed perch attention to the no-spine Bythotrephes. Although taste and palatability will have played a role in which prey was selected first, perch attacked half-spine Bythotrephes first over Daphnia indicating that it may have also been very conspicuous. However, when full-spine Bythotrephes were added, perch foraging decisions changed. It is unlikely that conspicuousness was altered; in fact, it was most likely increased due to the full-spine form's greater length. Alternatively, motion may have changed perceptibly. That perch attacked the no-spine form over the full-spine form in the final paired presentation indicates perch were able to distinguish between the two. However, differences in motion is unlikely to make the animal less palatable. It more likely aided the fish in determining which prey to avoid. Thus, although a higher degree of conspicuousness based on size or motion may have caused perch to select the no-spine and half-spine forms first over Daphnia, the greater spine length of the fullspine form appeared to counteract such selection. At no time, was Daphnia selected first over a Bythotrephes. This is most likely due to the fact that fish preferred the no-spine form over Daphnia to such an extent that they continued to attempt to ingest whatever form appeared to more closely resemble it. Thus, fish never showed a strong preference to attack Daphnia first.

Differences in the probabilities of rejection and ingestion of Bythotrephes with varying portions of the spine removed and in the juvenile stage strongly support the fact that the spine decreases Bythotrephes' palatability. Rejection, an indicator of handling difficulty, and ultimate ingestion significantly increases and decreases, respectively, as greater portions of the spine are left intact. These results indicate that it is indeed the spine that is responsible for the dramatic behaviors exhibited by perch in the first experiment, and the leading determinant of fish aversion to Bythotrephes. These results have implications for elongation of the spine, currently and historically. If Bythotrephes' spine exhibits polymorphism, an increase in spine length will have repercussions on survivorship, either by increasing the probability that the animal will not be ingested, or by inducing aversion in 
larger fish. In terms of the evolution of the spine, predators may have been the selective pressure necessary for the spine's initial lengthening.

Although the spine may have evolved for other purposes, it is currently of sufficient length and rigidity to act in post-contact defense against fish in their larval to juvenile life stages when fish are most dependent on zooplankton. Bythotrephes is a relatively large invertebrate (ca. $10 \mathrm{~mm}$ in length) that preys on similar zooplankton resources as young fish (MordukhaiBoltovskaia 1958; Lehman 1988) and so is likely to overlap temporally and spatially with young-of-the-year planktivores. Given that its greater size increases its conspicuousness to visual fish predators (e.g., Zaret 1980), Bythotrephes would certainly benefit from a defense against small fish predation.

The feeding trials with alternative prey closely approximate the natural situation many fish face as youngof-the-year planktivores. As a rule, Bythotrephes forms resting eggs over winter and does not usually appear in great abundance until early summer when temperatures rise. Thus, during spring, fish in their first year of life are feeding on daphnids and copepods and have not yet experienced Bythotrephes. The laboratory feeding trials indicate that when Bythotrephes appears in the plankton, young fish will most likely attack the animal due to its large size relative to other zooplankton. However, as fish experience with Bythotrephes increases, and their difficulty ingesting the animal continues, fish predators will be more likely to reject and less likely to ingest Bythotrephes. Fish may continue to try to ingest Bythotrephes as its density increases or they forget their previous encounters. However, given sufficient experience, fish are likely to learn aversion to Bythotrephes and cease to attack and capture it.

Although aversion results in a decline in prey consumption, its development coincides with a truncation in the predator's behavior. As results from the first experiment show, perch cease to follow the initial behavioral pathway (Fig. 2) step by step. First they cease to ingest Bythotrephes and instead reject it. Then they cease to recapture a Bythotrephes they reject. Finally, they cease to attack and capture Bythotrephes. Hoogland et al. (1957) describe a truncation in behavior when perch and pike (Esox spp.) develop aversion to spined sticklebacks. Both predators cease to ingest, then cease to capture, finally cease to attack the spined prey. Brower (1969) describes truncation in birds learning aversion to toxic monarch butterflies. A naive bird will attack, capture and ingest a monarch, while a more experienced bird will only attack and capture it. Finally, a bird averse to monarchs will not attack. Brower (1969) calls this the most efficient form of prey selection. The predation behaviors that "fall out" first appear to correspond to activities that require the highest intensity levels or drive (Manning 1972). Thus, a negative stimulus such as a spine or toxin might increase the response thresholds of each foraging behavior so that the predator is increasingly less likely to engage in the next behavior. This may be why a predator appears to reject a prey item with ever increasing efficiency as it progresses toward aversion.

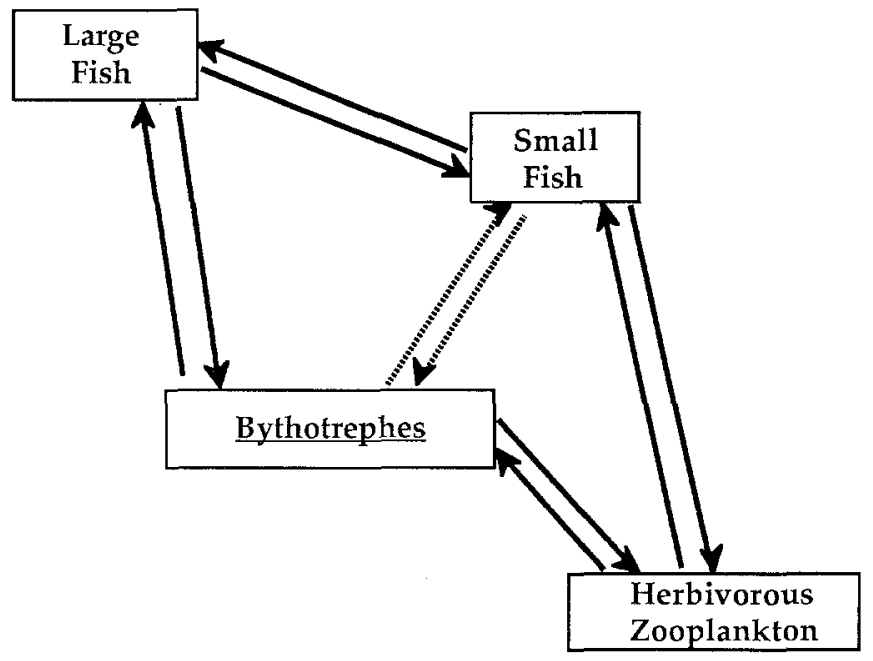

Fig. 6. Potential predator-prey interactions among Bythotrephes herbivorous zooplankton, and fish based on size. Both small fish and Bythotrephes risk predation from large fish and feed on herbivorous zooplankton; however, the competitive interaction between small fish and Bythotrephes depends on the degree to which the spine protects Bythotrephes from small fish predation

Not all predators are likely to exhibit such efficient prey selection against unpalatable prey. The telencephalon or forebrain in the fish has been implicated in its ability to perform avoidance behavior and is considered analogous to the mammal's limbic system (Flood and Overmier 1981). An experiment involving normal and forebrainless fish (Farr and Savage 1978) suggests that avoidance learning requires two types of learning: one of association, the other of reinforcement. When the forebrain is removed, a fish can still associate a cue with a negative situation and respond, but it appears unable to learn that its behavior terminates the negative situation, and is therefore unlikely to learn avoidance (Flood and Overmier 1981). This indicates that predators that can learn but are without behavioral mechanisms of reinforcement are unlikely to exhibit aversion.

In conclusion, fish aversion to Bythotrephes appears to be the transition in response from post-contact ingestion difficulty to pre-contact avoidance. With the spine functioning in post-contact defense, the probability that Bythotrephes will be attacked and captured is high given its large size, but the probability that it will be ingested is low. Likewise, the probability that fish predators will spend time and energy attempting to ingest a prey item they are likely to reject is high. However, with the spine functioning in pre-contact defense in which fish recognize Bythotrephes and avoid it, the zooplankter is less likely to be handled and injured, while fish predators do not waste time on an unpalatable food item. However, while such a response ensures greater foraging efficiency for small fish predators and higher survivorship for Bythotrephes, the ecological implications of aversion are more complex. Fig. 6 illustrates the relationships among herbivorous zooplankton, Bythotrephes and fish in a hypothetical lake. Large fish feed on smaller fish and 
Bythotrephes, while herbivorous zooplankton provide resources to both small fish and Bythotrephes. The interaction between small fish and Bythotrephes is one of competition for resources, but also one of predation. Small fish can attempt to utilize Bythotrephes as a food source and indirectly obtain the zooplankton resources Bythotrephes sequesters. However, with the development of small fish aversion to Bythotrephes, there is no longer any direct contact between the two, the competitive nature of their interaction becomes amplified, and the energy transfer from herbivorous zooplankters through a carnivorous zooplankter is effectively closed to small fish. Such a situation makes the position of the spined zooplankter in the food web more equal to that of the small vertebrate predator in terms of resource acquisition and vulnerability to predation.

Acknowledgements. I thank Kevin Kirk for comments on all phases of research and drafts of manuscript, Charles Kerfoot for ideas and comments on previous drafts of this manuscript, and anonymous reviewers. Thanks to Chris Starr, Bayport Aquaculture, and Terry Gray, Bluefin Charter, for help in collecting animals, the University of Michigan Biological Station (UMBS) for use of facilities, and the National Geographic Society for additional documentation and support. Funds were provided by UMBS, UM Rackham Graduate School and Michigan Sea Grant. This research was in partial fulfillment of the master's degree at the University of Michigan.

This publication is a result of work sponsored by the Michigan Sea Grant College Program, project number R/ES-6, under grant number NA89AA-D-SG083 from the Office of Sea Grant, National Oceanic \& Atmospheric Administration (NOAA), U.S. Department of Commerce, and funds from the State of Michigan. The U.S. Government is authorized to produce and distribute reprints for governmental purposes not withstanding any copyright notation appearing hereon.

\section{References}

Barnhisel DR (1990) Juvenile fish response to the cladoceran Bythotrephes cederstroemi. Master thesis, University of Michigan, Ann Arbor, MI USA

Barnhisel DR (1991) The caudal appendage of the cladoceran Bythotrephes cederstroemi as defense against young fish. J Plank Res 13:529-537

Brower LP (1969) Ecological chemistry. Scient Am 220:22-29

Brower LP, Brower JVZ (1962) Investigations into mimicry. Nat Hist $71: 8-19$

Brower LP, Brower JVZ, Corvino JM (1967) Plant poisons in a terrestrial food chain. Proc Natl Acad Sci 57:893-898

Edmunds M (1974) Defence in Animals; a survey of anti-predator devices. Longman, New York

Evans MS (1988) Bythotrephes cederstroemi: its new appearance in Lake Michigan. J Great Lakes Res 14:234-240

Garcia J, Hankins WG, Rusiniak KW (1974) Behavioral regulation of the milieu interne in man and rat. Science 185:824-831

Farr EJ, Savage GE (1978) First- and second-order conditioning in goldfish and their relation to the telencephalon. Behav Biol $22: 50-59$

Fisher RA (1958) The genetical theory of natural selection. Dover, New York

Flood NB, Overmier JB (1981) Learning in teleost fish: role of the telencephalon. In: PR Laming (ed) Brain mechanisms of behaviour in lower vertebrates. Cambridge University Press, Cambridge, pp 259-279

Forbes LS (1989) Prey defences and predator handling behaviour: the dangerous prey hypothesis. Oikos $55: 155-158$

Furnass TI (1979) Laboratory experiments on prey selection by perch fry (Perca fluviatilis). Freshwater Biol 9:33-43

Gilbert JJ (1966) Rotifer ecology and embryological induction. Science 151:1234-1237

Harvell CD (1984) Predator-induced defense in a marine bryozoan. Science 224: 1357-1359

Havel JE (1987) Predator-induced defenses: a review. In: Kerfoot WC, Sih A (eds) Predation; direct and indirect effects. University Press of New England, Hanover, pp 263-278

Havel JE, Dodson SI (1984) Chaoborus predation on typical and spined morphs of Daphnia pulex : behavioral observations. Limnol Oceanogr 29:487-494

Holling CS (1966) The functional response of invertebrate predators to prey density. Mem Ent Soc Can 48:3-86

Hoogland R, Morris D, Tinbergen N (1957) The spines of sticklebacks (Gasterosteus and Pygosteus) as means of defence against predators (Perca and Esox). Behav 10:205-236

Jacobs J (1965) Significance of morphology and physiology of Daphnia for its survival in predator-prey experiments. Naturwissenshaften $52: 141$

Kerfoot WC (1982) A question of taste: crypsis and warning coloration in freshwater zooplankton communities. Ecology $63: 538-554$

Lehman JT (1988) Algal biomass unaltered by food-web changes in Lake Michigan. Nature 332:537-538

Lorenz KZ (1981) The foundations of ethology. Springer, Berlin Heidelberg New York

Manning A (1972) An introduction to animal behavior (2nd ed). Addison-Wesley, London

Mills EL, Forney JL (1981) Energetics, food consumption, and growth of young yellow perch in Oneida Lake, New York. Trans Am Fish Soc 1 10:479-488

Mordukhai-Boltovskaia ED (1958) Preliminary notes on the feeding of the carnivorous cladocerans Leptodora kindti and Bythotrephes. Dokl Akad Sci SSSR 122:828-830

Morgan SG (1989) Adaptive significance of spination in estuarine crab zoeae. Ecology 70:464-482

Reist JD (1980) Selective predation upon pelvic phenotypes of brook stickleback, Culaea inconstans, by northern pike, Esox lucius. Can J Zool 58:1245-1252

Ross DM (1971) Protection of hermit crabs (Dardanus spp.) from octopus by commensal sea anemones (Calliactus spp.). Nature 230: $401-402$

Sokal RR, Rohlf FJ (1981) Biometrics (2nd ed). WH Freeman and Company, San Francisco

Young CM (1986) Defenses and refuges: alternative mechanisms of coexistence between a predatory gastropod and its ascidian prey. Mar Biol 91:513-522

Zaret TM (1980) Predation and freshwater communities. Yale University Press, New Haven 